\title{
Clinical management of incidental findings on pelvic adnexal masses
}

\author{
Daniel Spadoto Dias ${ }^{1 *}$, flávia Neves Bueloni-Dias ${ }^{2}$, Armando Delmanto ${ }^{1}$, Ângela Favorito Santarém Tonon ${ }^{1}$, \\ Najla Mohamad Tayfour ${ }^{3}$, Paulo Traiman ${ }^{4}$, Rogério Dias ${ }^{5}$ \\ ${ }^{1}$ PhD - Assistant Physician, Department of Gynecology and Obstetrics, Faculdade de Medicina de Botucatu, Universidade Estadual Paulista Júlio de Mesquita Filho (UNESP), Botucatu,SP, Brazil \\ ${ }^{2} \mathrm{MSC}$ - Assistant Physician, Department of Gynecology and Obstetrics, Faculdade de Medicina de Botucatu, UNESP, Botucatu, SP, Brazil \\ ${ }^{3} \mathrm{MD}$ - Assistant Physician, Gynecology Service, Division of Pelvic Oncogynecology, Hospital do Servidor Público Estadual (IAMSPE), São Paulo, SP, Brazil \\ ${ }^{4}$ Livre Docência - Adjunct Professor, Head of the Division of Gynecologic Oncology, Department of Gynecology and Obstetrics, Faculdade de Medicina de Botucatu, UNESP, Botucatu,SP, Brazil \\ 5Livre Docência - Adjunct Professor, Head of the Division of Gynecologic Endoscopy and Family Planning, Department of Gynecology and Obstetrics, Faculdade de Medicina de Botucatu, UNESP, Botucatu,SP, Brazil
}

Studed conducted at Programa de Pós-graduação em Ginecologia Obstetrícia e Mastologia (PGGOM) Faculdade de Medicina de Botucatu, Universidade Estadual Paulista Júlio de Mesquita Filho (FMB/UNESP), Botucatu, SP, Brazil

Article received: 6/16/2014 Accepted for publication: 6/17/2014

*Correspondence: Address: Distrito de Rubião Júnior, $s / n^{\circ}$ Botucatu, SP - Brazil Postal code: 18618-970 dspdias@hotmail.com

http://dx.doi.org/10.1590/1806-9282.61.05.469

\section{SUMmARY}

Due to widespread use of pelvic and transvaginal ultrasound in routine gynecological evaluation, the incidental finding of adnexal masses has led to discussions about management in asymptomatic patients regarding the risk of ovarian cancer. Transvaginal ultrasonography remains the modality of choice in the evaluation of suspicious characteristics. The combined analysis of ultrasound morphological parameters with Doppler study, serum carcinona antigen 125 and investigation of a symptom index may improve diagnosis. Surgical approach should be considered whenever there are suspicious images, rapid growth of cysts, changes in the appearance compared to the initial evaluation or when the patient has symptoms. Future studies on genetic and molecular mechanisms may help explain the pathophysiology of ovarian cancer, improving early diagnosis and treatment.

Keywords: ovarian cysts, ovarian neoplasm's, adnexal diseases, ultrasonography, CA-125 antigen.

\section{INTRODUCTION}

Due to the wide use of pelvic and transvaginal ultrasound for routine gynecological evaluation, during the reproductive years and after menopause, the incidental finding of adnexal masses has been observed in a growing proportion of women, leading to discussions on the approach to be used in asymptomatic patients ${ }^{1}(\mathbf{B})$. One of the main concerns of the gynecologist is the identification of risk markers for the development of ovarian cancer, which may lead to early surgical treatment and prevent progression of the disease during the expectant conservative treatment.

Approximately 255,000 new cases of ovarian cancer are diagnosed each year worldwide, causing approximately 140,000 deaths in the period, which puts ovarian cancer in $7^{\text {th }}$ place among the causes of cancer death among women $^{2}(\mathbf{A})$. In Latin America, the incidence of this cancer is at 8:100,000 women; in 2012, 6,190 new cases of ovarian cancer were estimated in Brazil, with an assessed risk of $6: 100,000^{3}(\mathbf{B})$.

Women with ovarian cancer usually have nonspecific symptoms, such as mild abdominal pain, bloating, changes in defecation frequency, and urinary symptoms, making early detection very difficult ${ }^{4}(\mathbf{A})$. Thus, the diagnosis is delayed in three out of four patients, leading to advanced stage of disease and extra-pelvic spread, which limits the effectiveness of therapy and jeopardizes the survival of these women ${ }^{5}(\mathbf{C})$. Unfortunately, due to the low positive predictive value of potential tests for population screening, such as carcinoma antigen 125 (CA-125) and ultrasound, there is currently no screening strategy for ovarian cancer ${ }^{4}(\mathbf{A})$.

The objective of this review is to present the current evidence and recommendations for clinical management of incidental adnexal masses and to identify malignancy suspicious signs in asymptomatic women.

\section{Physiological and molecular aspects}

A major problem in diagnostic clarification of incidental findings on ultrasound is the characterization of the malignant potential of the lesions. Ovarian cancer, being a heterogeneous disease, is composed of different types of tumors derived from different cell lines with dif- 
ferent behaviors and clinical-pathological characteris$\operatorname{tics}^{6}(\mathbf{C})$. There are three main categories which are responsible for almost all malignant tumors: surface epithelial-stromal tumors, sex cord-stromal tumors and germ cell tumors, so that epithelial ovarian carcinomas account for $90-95 \%$ of all cases of malignant disease ${ }^{5}$ (C). Germ cell tumors and sex cord-stromal tumors account for the remaining 5 to $10 \%$ and, due to their unique characteristics, they require specific management that will not be included in this review.

Based on a series of morphological and molecular genetic studies, a dualistic model was proposed, for teaching purposes, which divides the multiple types of epithelial ovarian cancers into two groups, called type I and type II, considering common characteristics of the different tumors that make up each group ${ }^{7}(\mathbf{C})$. Type I tumors are clinically indolent, with low histologic grade, and are usually diagnosed at early stages of disease, when the lesion is still confined to the ovary ${ }^{6,7}(\mathbf{C})$. Their histological subtypes have a distinct cell line ranging from benign cystic tumors and their corresponding carcinomas, often presenting an intermediate stage, the so called borderline tumors, supporting the hypothesis of a continuous progression in the development of these tumors ${ }^{6}(\mathbf{C})$. Lowgrade serous tumors, low-grade endometrioid tumors, clear cell tumors and mucinous carcinomas are all part of type $\mathrm{I}^{7}(\mathbf{C})$.

Opposite to the different morphological features observed in type I tumors, morphological differences among type II tumors are more subtle, resulting in a considerable overlapping of diagnoses made by different pathologists ${ }^{6}$ (C). Type II tumors have rapid evolution and are characterized by the presence of papillary or glandular vegetation and the presence of solid areas, with diagnoses of highgrade serous tumors, high-grade endometrioid tumors, mixed mesodermal tumors (carcinosarcomas) or undifferentiated carcinomas, depending on their predominant pat$\operatorname{tern}^{6,7}(\mathbf{C})$. Type II tumors are highly aggressive and almost always diagnosed in advanced stages of the disease. They are responsible for approximately $75 \%$ of all epithelial ovarian carcinomas, with relatively similar morphological characteristics, and a uniformly poor prognosis ${ }^{6}(\mathbf{C})$.

Recent studies have shown that the morphological differences between type I and type II tumors are mirrored by distinct genetic-molecular characteristics. In general, it can be said that type I tumors are genetically more stable, exhibit a characteristic pattern of mutations in genes such as KRAS, BRAF, ERBB2, PTEN, CTNNB1 and $P I K 3 C A$, and occur in specific histological types. Type II tumors, in turn, exhibit more morphological and molec- ular homogeneity. They are genetically unstable and have a high frequency of mutations in the TP53 gene (> 80\% of cases), also with CCNE1 gene amplification ${ }^{6}(\mathbf{C})$. These results suggest that different types of ovarian carcinomas develop through different molecular pathways explaining differences in behavior and clinical-pathological.

\section{LABORATORY AND IMAGE ASPECTS}

In case of incidental finding of adnexal mass pelvic, transvaginal ultrasonography remains the modality of choice for evaluating suspicious characteristics ${ }^{4}(\mathbf{A})$. In the presence of any abnormality detected during a screening test or when there are doubts about the interpretation of the images obtained, a second opinion from a sonographer with extensive experience in oncology imaging is recom$\operatorname{mended}^{1}(B)$.

Several scoring systems based on ultrasound morphology of adnexal cysts have been proposed to differentiate benign lesions from malignant adnexal masses ${ }^{8-14}$ (B). These scoring systems are based on specific parameters such as surface, thickness of the wall, and cyst echogenicity; cyst volume; presence, thickness and number of septa; presence, size and number of vegetation, and presence and size of solid areas within the cyst.

According to the classification of the International Ovarian Tumor Analysis Group (IOTA Group), abnormal adnexal morphology can be classified as follows:

- Unilocular cyst: ovary has a single cyst, thin-walled, anechoic measuring over $10 \mathrm{~mm}$ in diameter. This includes cysts without septa or papillary and also those with incomplete septa, papillae measuring less than $3 \mathrm{~mm}$ and irregular walls;

- Multilocular cyst: ovary has a cyst with at least one complete septum or multicystic;

- Unilocular solid cyst: ovary has a single cyst, thinwalled, with no septa, and at least one solid or papillary component measuring $3 \mathrm{~mm}$ or more;

- Multilocular solid cyst: ovary has a cyst with a minimum of one complete septum, along with a solid area or papillary structure of $3 \mathrm{~mm}$ or more;

- Solid mass: ovary has a mass with over $80 \%$ solid area.

According to this classification, findings consistent with solid mass and multilocular solid mass have the highest probability of malignant changes, followed by findings of unilocular solid mass and multilocular cyst, while the unilocular cyst has the lowest probability of malignan$\mathrm{cy}^{15}(\mathbf{B})$. All proposed scoring systems appear to exhibit an acceptable level of sensitivity and specificity, ranging 
from 83.5 to $92 \%$ and from 63 to $97 \%$, respectively ${ }^{8,11-14}$ (B). The choice of the scoring system may, therefore, be based on the preference of the observer ${ }^{4}(\mathbf{A})$.

The malignancy risk index (MRi) is a rule of clinical prediction that includes CA-125 and menopause status in its assessment, as well as ultrasound morphology ${ }^{9}(\mathbf{B})$. The sensitivity and specificity of this index, when using a cutoff level of 200, are described at approximately 79.2 and $91.7 \%$, respectively ${ }^{4,9}(\mathbf{A})(\mathbf{B})$. As an autonomous examination, CA125 is not recommended to differentiate benign and malignant adnexal masses, since several benign conditions may increase its serum levels ${ }^{3,4}(\mathbf{B})(\mathbf{A})$. Since the incidence of ovarian cancer compared with benign gynecological conditions is lower in women who are premenopausal, the CA- 125 is of limited use to track the population. In the early stages of ovarian cancer, only $50 \%$ of cases have elevated CA- 125 levels, and the interpretation of these values should be done carefully $^{4,16}(\mathbf{A})$. With a threshold of $35 \mathrm{U} / \mathrm{mL}$, CA-125 has an overall sensitivity of $78.7 \%$ and specificity of $77.9 \%{ }^{4}$ (A).

When conventional ultrasound examination is not satisfactory, three-dimensional ultrasonography (3D) can be recommended as it offers superior sensitivity and specificity, described in the literature around 93.5 and $91.5 \%{ }^{17-19}$ (B). Magnetic resonance imaging (MRI) may be appropriate for analysis of adnexal cysts to help clarify the potential for malignancy with a sensitivity and specificity of 91.9 and $88.4 \%$, respectively ${ }^{20,21}(\mathbf{B})$. In cases where there is suspicion of extra-ovarian involvement, computed tomography (CT) is the most useful technique with a sensitivity of $87.2 \%$ and specificity of $84.0 \% \%^{4,22,23}(\mathbf{A})(\mathbf{B})$.

Doppler investigation alone in the evaluation of adnexal masses is not recommended and should always be combined with a morphological evaluation ${ }^{4}(\mathbf{A})$. Metaanalysis studies on resistance index, pulsatility index and systolic peak velocity found sensitivity and specificity for each index at 77.2 and $89.8 \%, 80.6$ and $79.9 \%$, and 80.0 and $84.2 \%$, respectively ${ }^{4,17,19}(\mathbf{A})(\mathbf{B})$. The evaluation of adnexal findings by Doppler study using resistance index, pulsatility index and maximum systolic velocity did not show diagnostic accuracy greater than that of conventional ultrasound. Also, due to the overlap of vascular parameters between malignant and benign masses, a firm diagnosis based on the assessment only by Doppler can be quite difficult ${ }^{4}$ (A).

\section{GOOd PRACTICES IN TREATMENT}

Ovarian cysts are relatively common finding on ultrasound, especially in postmenopausal women, with an estimated incidence of up to $21 \%$ in this population ${ }^{1}(\mathbf{B})$. Due to the potential morbidity of surgical treatments, clinical monitoring may be recommended since a large proportion of these cysts are associated with low risk for developing ovarian cancer $^{1,24}(\mathbf{B})$.

In a multicenter clinical trial for the screening of ovarian cancer in the United Kingdom (The United Kingdom Colaborative Trial of Ovarian Cancer Screening - UKCTOCS), in which 48,053 postmenopausal women were analyzed, it was observed that the rate of morphological changes, according to IOTA classification, was 9.1\% (95CI 8.8-9.3\%). The absolute risk for any type of epithelial ovarian cancer (type I, borderline and type II) associated with adnexal morphological changes was $1.08 \%$ (95CI, $0.79-1.43 \%$ ) for a period of 3 years, while in the subgroup of patients who had solid elements on ultrasound (solid unilocular, multilocular solid and massive) the absolute risk was $4.45 \%(95 \mathrm{CI}, 3.08-6.20 \%)^{1}$ (B). Despite the higher prevalence of type II epithelial tumors, ultrasonography presented, in this study, better diagnostic capacity for the detection of borderline and type I tumors, most likely due to the indolent nature of these lesions, which allows ultrasound monitoring and the observation of pattern changes over time.

Valentin et al. analyzing 1148 unilocular cysts according to the IOTA classification, found an overall malignancy rate of $0.96 \%$ (95CI, $0.48-1.71 \%$ ), with a higher prevalence of malignant lesions in postmenopausal compared to premenopausal women $(0.54 \%$ (95CI, $0.17-1.25 \%)$ vs. $2.76 \%$ (95CI, 1.02-5.92\%), $\mathrm{p}=0.009)^{24}(\mathbf{B})$. Personal history of breast cancer $(18 \%$ vs. $2 \%, \mathrm{p}=0.02)$ or ovarian cancer $(18 v$ s. $0.6 \%, \mathrm{p}=0.003)$ and the presence of hemorrhagic content in the cyst ( $18 v$ s. $2 \%, \mathrm{p}=0.03)$ showed a positive association with malignant cysts. In $63.6 \%$ of malignant lesions diagnosed as unilocular cysts on ultrasound, papillary projections or other solid components were found in macroscopic inspection of the surgical specimen ${ }^{24}(\mathbf{B})$.

In another prospective study including 166 premenopausal women, Alcázar et al. found that $38.5 \%$ of adnexal cysts with benign aspect had spontaneous resolution in an average period of 40 months, $25.5 \%$ remained unchanged for a median of 88 months (36-192 months) and $20.8 \%$ were surgically removed due to increase in cyst size, change in appearance of the cyst, clinical suspicion of adnexal torsion, surgery combined with another procedure for uterine disease and the patient's own decision. Only two cases of ovarian cancer were observed in this series, both epithelial type I, with an absolute risk of $0.9 \%$ (95CI, 0.01-3.08\% $)^{25}(\mathbf{B})$. According to the authors, expectant management for adnexal cysts with benign morphology seems to be a reasonable option in selected cases of asymptomatic premenopausal women. 
Surgical approach should be considered whenever there are suspicious changes on imaging studies, the adnexal cyst presents rapid growth or change in its appearance from the initial assessment, or the patient experiences symptoms related to the cyst. Despite the lack of specific clinical symptoms, a recent study showed that the evaluation of a symptom index composed of abdominal bloating and/or increased abdominal size, pelvic and/or abdominal pain, and inability to eat normally and/or rapid feeling of fullness may exhibit a sensitivity of $78.3 \%$ and a specificity of $60.3 \%$ in discriminating malignant diseases (OR 5.5; 95CI, $2.7-11.3 \%)^{3}(\mathbf{B})$. In many cases, during preoperative evaluation, a discussion with a gynecological oncologist is recommended to analyze the therapeutic proposal.

As a route to approach adnexal masses with suspected malignancy, laparoscopy seems to be a reasonable alternative to laparotomy, provided that the staging operation can be performed appropriately, where indicated, and in cases without disseminated disease ${ }^{26}(\mathbf{B})$. The choice between laparoscopy and laparotomy should be based on the patient and the surgeon's preference and experience ${ }^{4}$ (A). Intraoperative pathological study by freezing, when available, is recommended for the diagnosis of suspicious adnexal masses and especially to assess the need to extend surgery. Freezing, although inconclusive in many circumstances, has a sensitivity around $89.2 \%$ and a specificity of $97.9 \%{ }^{4}(\mathbf{A})$.

To improve the survival of patients with ovarian cancer at an early stage, comprehensive surgical staging with lymphadenectomy is recommended. Two large populationbased studies found an improvement in disease-free survival after 3 years $(\mathrm{p}<0.001)$ and 5 years $(\mathrm{p}<0.001)$ in $\mathrm{pa}$ tients undergoing surgical staging with lymphadenectomy, compared to procedures performed without lymphadenectomy $y^{27,28}(\mathbf{B})$. Oksefjell et al. reported a statistically significant improvement in overall survival at 5 years in patients undergoing lymphadenectomy compared with those not undergoing the procedure (87 vs. $64 \%, \mathrm{p}=0.02)^{29}(\mathbf{B})$.

Surgery to preserve fertility is an acceptable alternative in patients with low-grade malignant tumors and in the case of histologically well-differentiated tumors on initial surgical stages (FIGO grade I). Yinon et al. compared the recurrence rates of borderline tumors in $40 \mathrm{pa}-$ tients who underwent unilateral salpingo-oophorectomy with 22 patients treated only with cystectomy, and found no statistical differences (27.5 vs. $22.7 \%, \mathrm{p}=0.8)^{30}(\mathbf{B})$. Likewise, in a study including 360 with borderline tumors, Park et al. did not find any statistical difference in terms of disease-free survival among patients undergoing radical surgery or with fertility preservation $(\mathrm{p}=0.651)^{31}(\mathbf{B})$.

\section{Conclusion}

Due to the low likelihood of ovarian cancer in incidental findings of adnexal pelvic masses, and because of the high rates of spontaneous resolution, ultrasound monitoring can be performed with good early diagnosis rates for borderline and type I tumors. The frequency of these revaluations should be established individually and according to the routine of each service. However, early screening of type II tumors remains a challenge.

Due to the fact that the risk of malignancy is increased in lesions containing septa and/or solid components, it is extremely important that the examiner performs a thorough search for papillary projections and solid elements in any adnexal cyst, even if it appears to be unilocular on ultrasound. Also, menopausal status assessment and the presence of personal and family history of gynecological cancers should always be taken into consideration, due to the increased risk of malignancy in these patients.

The combined analysis of morphological parameters on ultrasound and Doppler study, CA-125 levels, and the assessment of a symptom index composed of abdominal bloating and/or increased abdominal size, pelvic and/or abdominal pain, and inability to eat normally and/or rapid feeling of fullness may increase diagnostic rates. Even with all the current technology and knowledge on the subject, it is not clinically possible to fully differentiate benign and malignant lesions preoperatively. Thus, pathological analysis remains the gold standard for definitive diagnosis. The route to approach adnexal masses should be based on the patient and the surgeon's preference and experience, provided that adequate staging can be performed, whenever indicated.

Despite numerous definitions and criteria to establish the best ovarian cancer screening method, the number of deaths from the disease has not fallen substantially in recent years ${ }^{5}(\mathbf{C})$. A better understanding of genetic and molecular mechanisms may be the key that will bring light to new knowledge about the development of ovarian cancer, its diagnosis and treatment.

\section{Resumo}

Manejo clínico dos achados incidentais de massas pélvicas anexiais

Em virtude da ampla utilização da ultrassonografia pélvica e transvaginal na avaliação ginecológica de rotina, o achado incidental de massas anexiais tem ocasionado discussões sobre a conduta em pacientes assintomáticas frente ao risco de desenvolvimento do câncer de ovário. A ultrassono- 
grafia transvaginal continua a ser a modalidade de primeira escolha na avaliação de características suspeitas. A análise conjunta de parâmetros morfológicos ultrassonográficos com o estudo Doppler, a pesquisa de CA-125 e a investigação de índice de sintomas pode incrementar as taxas de diagnóstico. Abordagem cirúrgica deve ser considerada sempre que houver alterações em exames de imagem, quando houver crescimento rápido do cisto, mudanças em seu aspecto em relação à avaliação inicial ou quando a paciente apresentar sintomatologia. Uma compreensão melhor de mecanismos genéticos e moleculares pode auxiliar na elucidação da fisiopatologia do câncer ovariano, aprimorando seu diagnóstico e tratamento precoces.

Palavras-chave: cistos ovarianos, neoplasias ovarianas, doenças dos anexos, ultrassonografia, antígeno CA-125.

\section{References}

1. Sharma A, Apostolidou S, Burnell M, Campbell S, Habib M, Gentry-Maharaj $\mathrm{A}$, et al. Risk of epithelial ovarian cancer in asymptomatic women with ultrasound-detected ovarian masses: a prospective cohort study within the UK collaborative trial of ovarian cancer screening (UKCTOCS). Ultrasound Obstet Gynecol. 2012; 40(3):338-44.

2. Jemal A, Bray F, Center MM, Ferlay J, Ward E, Forman D. Global cancer statistics. CA Cancer J Clin. 2011; 61(2):69-90.

3. Pitta Dda R, Sarian LO, Barreta A, Campos EA, Andrade LL, Fachini AM, et al. Symptoms, CA-125 and HE4 for the preoperative prediction of ovarian malignancy in Brazilian women with ovarian masses. BMC Cancer. 2013; 13:423.

4. Dodge JE, Covens AL, Lacchetti C, Elit LM, Le T, Devries-Aboud M, et al. Management of a suspicious adnexal mass: a clinical practice guideline. Curr Oncol. 2012; 19(4):e244-57.

5. Schorge JO, Williams JW. Williams gynecology. New York: McGraw-Hill Medical, 2008.

6. Kurman RJ, Shih Ie M. The origin and pathogenesis of epithelial ovarian cancer: a proposed unifying theory. Am J Surg Pathol. 2010; 34(3):433-43.

7. Shih Ie M, Kurman RJ. Ovarian tumorigenesis: a proposed model based on morphological and molecular genetic analysis. Am J Pathol. 2004; 164(5):1511-8.

8. Finkler NJ, Benacerraf B, Lavin PT, Wojciechowski C, Knapp RC. Comparison of serum CA 125, clinical impression, and ultrasound in the preoperative evaluation of ovarian masses. Obstet Gynecol. 1988; 72(4):659-64.

9. Jacobs I, Oram D, Fairbanks J, Turner J, Frost C, Grudzinskas JG. A risk of malignancy index incorporating CA 125 , ultrasound and menopausal status for the accurate preoperative diagnosis of ovarian cancer. Br J Obstet Gynaecol. 1990; 97(10):922-9.

10. Sassone AM, Timor-Tritsch IE, Artner A, Westhoff C, Warren WB. Transvaginal sonographic characterization of ovarian disease: evaluation of a new scoring system to predict ovarian malignancy. Obstet Gynecol. 1991; 78(1):70-6.

11. DePriest PD, Shenson D, Fried A, Hunter JE, Andrews SJ, Gallion HH, et al. A morphology index based on sonographic findings in ovarian cancer. Gynecol Oncol. 1993; 51(1):7-11.

12. Lerner JP, Timor-Tritsch IE, Federman A, Abramovich G. Transvaginal ultrasonographic characterization of ovarian masses with an improved, weighted scoring system. Am J Obstet Gynecol. 1994; 170(1 Pt 1):81-5.
13. Ferrazzi E, Zanetta G, Dordoni D, Berlanda N, Mezzopane R, Lissoni AA. Transvaginal ultrasonographic characterization of ovarian masses: comparison of five scoring systems in a multicenter study. Ultrasound Obstet Gynecol. 1997; 10(3):192-7.

14. Amor F, Vaccaro H, Alcazar JL, Leon M, Craig JM, Martinez J. Gynecologic imaging reporting and data system: a new proposal for classifying adnexal masses on the basis of sonographic findings. J Ultrasound Med. 2009; 28(3):285-91.

15. Timmerman D, Valentin L, Bourne TH, Collins WP, Verrelst H, Vergote I, et al. Terms, definitions and measurements to describe the sonographic features of adnexal tumors: a consensus opinion from the International Ovarian Tumor Analysis (IOTA) Group. Ultrasound Obstet Gynecol. 2000; 16(5):500-5.

16. NIH consensus conference. Ovarian cancer. Screening, treatment, and followup. NIH Consensus Development Panel on Ovarian Cancer. JAMA. 1995; 273(6):491-7

17. Alcazar JL, Galan MJ, Garcia-Manero M, Guerriero S. Three-dimensional sonographic morphologic assessment in complex adnexal masses: preliminary experience. J Ultrasound Med. 2003; 22(3):249-54.

18. Alcazar JL, Castillo G. Comparison of 2-dimensional and 3-dimensional power-Doppler imaging in complex adnexal masses for the prediction of ovarian cancer. Am J Obstet Gynecol. 2005; 192(3):807-12.

19. Laban M, Metawee H, Elyan A, Kamal M, Kamel M, Mansour G. Threedimensional ultrasound and three-dimensional power Doppler in the assessment of ovarian tumors. Int J Gynaecol Obstet. 2007; 99(3):201-5.

20. Sohaib SA, Mills TD, Sahdev A, Webb JA, Vantrappen PO, Jacobs IJ, et al. The role of magnetic resonance imaging and ultrasound in patients with adnexal masses. Clin Radiol. 2005; 60(3):340-8.

21. Booth SJ, Turnbull LW, Poole DR, Richmond I. The accurate staging of ovarian cancer using 3T magnetic resonance imaging - a realistic option. BJOG. 2008; 115(7):894-901.

22. Buist MR, Golding RP, Burger CW, Vermorken JB, Kenemans P, Schutter $\mathrm{EM}$, et al. Comparative evaluation of diagnostic methods in ovarian carcinoma with emphasis on CT and MRI. Gynecol Oncol. 1994; 52(2):191-8.

23. Tsili AC, Tsampoulas C, Argyropoulou M, Navrozoglou I, Alamanos Y, Paraskevaidis E, et al. Comparative evaluation of multidetector CT and MR imaging in the differentiation of adnexal masses. Eur Radiol. 2008; 18(5):1049-57.

24. Valentin L, Ameye L, Franchi D, Guerriero S, Jurkovic D, Savelli L, et al. Risk of malignancy in unilocular cysts: a study of 1148 adnexal masses classified as unilocular cysts at transvaginal ultrasound and review of the literature. Ultrasound Obstet Gynecol. 2013; 41(1):80-9.

25. Alcazar JL, Olartecoechea B, Guerriero S, Jurado M. Expectant management of adnexal masses in selected premenopausal women: a prospective observational study. Ultrasound Obstet Gynecol. 2013; 41(5):582-8.

26. Canis M, Pouly JL, Wattiez A, Mage G, Manhes H, Bruhat MA. Laparoscopic management of adnexal masses suspicious at ultrasound. Obstet Gynecol. 1997; 89(5 Pt 1):679-83.

27. Chan JK, Munro EG, Cheung MK, Husain A, Teng NN, Berek JS, et al. Association of lymphadenectomy and survival in stage I ovarian cancer patients. Obstet Gynecol. 2007; 109(1):12-9.

28. Chan J, Fuh K, Shin J, Cheung M, Powell C, Chen LM, et al. The treatment and outcomes of early-stage epithelial ovarian cancer: have we made any progress? Br J Cancer. 2008; 98(7):1191-6.

29. Oksefjell H, Sandstad B, Trope C. Is the watch and wait approach adequate after comprehensive surgical staging in invasive stage I epithelial ovarian cancer? The Norwegian Radium Hospital experience. Eur J Gynaecol Oncol. 2008; 29(6):583-9.

30. Yinon Y, Beiner ME, Gotlieb WH, Korach Y, Perri T, Ben-Baruch G. Clinical outcome of cystectomy compared with unilateral salpingo-oophorectomy as fertility-sparing treatment of borderline ovarian tumors. Fertil Steril. 2007; 88(2):479-84.

31. Park JY, Kim DY, Kim JH, Kim YM, Kim YT, Nam JH. Surgical management of borderline ovarian tumors: The role of fertility-sparing surgery. Gynecol Oncol. 2009; 113(1):75-82. 